\title{
Acral lentiginous melanoma of the foot and ankle: A case series and review of the literature Ivan R Bristow*1 and Katharine Acland ${ }^{2}$
}

\author{
Address: ${ }^{5}$ School of Health Sciences, University of Southampton, UK and ${ }^{2}$ St Johns Institute of Dermatology, St Thomas' Hospital, London, UK \\ Email: Ivan R Bristow* - ib@soton.ac.uk; Katharine Acland - ib@soton.ac.uk \\ * Corresponding author
}

Published: 15 September 2008

Journal of Foot and Ankle Research 2008, I:II doi:10.1 I86/I757-II46-I-II

This article is available from: http://www.jootankleres.com/content/I/I/I I

(c) 2008 Bristow and Acland; licensee BioMed Central Ltd.

This is an Open Access article distributed under the terms of the Creative Commons Attribution License (http://creativecommons.org/licenses/by/2.0), which permits unrestricted use, distribution, and reproduction in any medium, provided the original work is properly cited.
Received: 13 May 2008

Accepted: 15 September 2008

\begin{abstract}
Background: Acral lentiginous melanoma (ALM) is an uncommon, cutaneous malignant tumour which may arise on the foot. Its relative rarity, atypical appearance and late presentation frequently serve as poor prognostic indicators.

Methods: At a tertiary skin tumour centre, a retrospective review was undertaken of all patients diagnosed with the tumour at the level of ankle or below.

Results: Over a six year period, 27 cases ( 20 female, 7 male) were identified with positive histology confirming the disease. The age ranged from 35-96 years of age (mean 62.7 years). The majority of the cohort were white $(59 \%)$ with plantar lesions $(62 \%) .33 \%$ of patients were initially were diagnosed incorrectly. The average time taken from the point of recognition, by the patient, to the lesion being correctly diagnosed was around 13.5 months.
\end{abstract}

Conclusion: Earlier diagnosis of ALM requires education at both a patient and practitioner level.

\section{Background}

Melanoma is a malignant tumour arising from melanocytes. The number of cases of the disease worldwide is increasing faster than any other form of cancer amongst Caucasians[1]. Although the disease is uncommon in the $\mathrm{UK}$, the incidence of cutaneous melanoma continues to rise and it has been calculated that the lifetime risk for developing the disease is 1:120 for men and 1:95 for women[2]. Currently there are around 8500 new cases annually in the UK with around 1800 melanoma related deaths[3]. Australia has the highest annual incidence of melanoma in the world. The lifetime risk of developing melanoma before the age of 75 is 1: 24 for males and 1:34 for females. In 2003, there were 9,524 new cases of melanoma reported in Australia with an annual death rate of around 1500[4]. Cutaneous melanoma can develop at any site. The lower limb represents around 30\% of all primary cutaneous melanomas, particularly in women, with the foot and ankle representing 3-15\% of all cutaneous melanomas[5].

\section{Sub-types of Melanoma}

Malignant melanoma (MM) is the commonest malignancy observed in the foot[6]. In 1969, Clark et al[7] histologically identified three sub-types - superficial spreading melanoma (SSM), nodular melanoma (NM) and lentigo maligna melanoma (LMM). In 1976, a fourth type, acral lentiginous melanoma (ALM) was added by Reed[8]. All sub-types of melanoma have been reported to arise on the foot with the exception of the LMM which occurs almost exclusively on the face[9]. 


\section{Acral Lentiginous Melanoma}

The term ALM was first described by Reed[8] as a subtype of melanoma. It was so named because of its predilection of acral (distal) areas of the body, particularly the palms, soles and the sub-ungual areas, and its distinct radial or "lentiginous" growth phase. ALM represents the rarest of the four sub-types of cutaneous melanoma yet is the most common variety diagnosed on the foot[10]. Reed described its diagnosis as being based on its histological, intra-dermal features showing a diffuse proliferation of large atypical melanocytes along the epidermal-dermal junction which is dispersed in a lentiginous pattern with marked acanthosis and elongation of the rete ridges[8]. When reviewing terminology within the literature, confusion often arises with the use of the term "acral" with some papers describing "acral melanoma" which is merely an anatomical term for any sub-type of melanoma located on the palms, soles or sub-ungual region.

ALM (figure 1) is the only sub-type of melanoma that occurs at the same rate in all races[11]. However, research data have demonstrated that melanomas in acral locations account for only around $1-7 \%$ of all cutaneous melanomas in Caucasians but has been shown to be significantly higher in Asian[12,13], Chinese[14,15], Japanese[16], Middle Eastern[17] and African

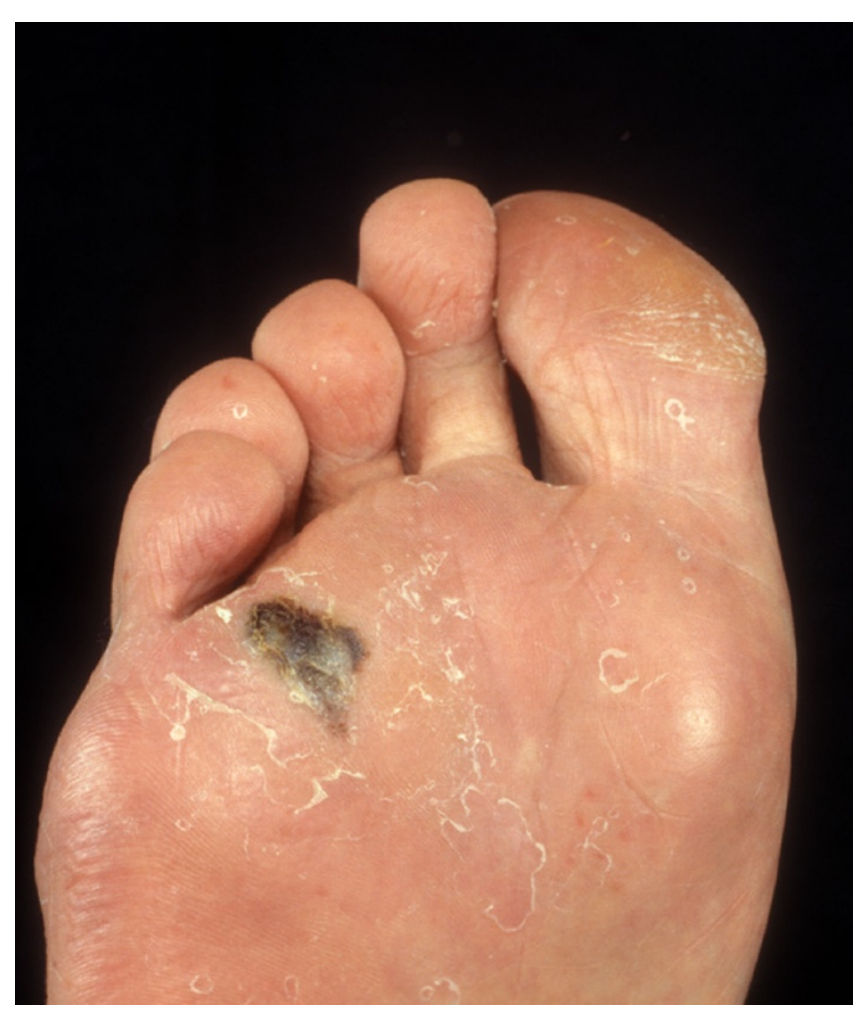

Figure I

Acral lentiginous melanoma on the plantar surface. populations $[18,19]$. This data reflects the low incidence of melanomas elsewhere on the body in the more pigmented skin types.

\section{Aetiology}

As ALM occurs equally across all races, predominantly on an area that seldom receives much sun exposure it has been suggested that the aetiology is different to that of other sub-types of melanoma or that sun exposure is a lesser risk factor than melanoma elsewhere. Green et al[20] undertook a case control study of 275 melanomas diagnosed on the soles and palms to investigate risk factors. Interestingly, they found that sun exposure was a significant risk factor in the development of ALM despite their plantar and nail bed location. Furthermore, a high mole count on the soles and elsewhere on the body were associated risk factors ( $\mathrm{RR}=6.395 \% \mathrm{CI} 2.5-15.6)$. Reinforcing this belief, other studies have demonstrated that increased sun exposure in an individual leads to the development of higher numbers of moles, especially in children[21].

Trauma as a cause has also been proposed as a possible risk factor for the development of ALM[20]. Penetrative injury of the foot showed significant association $(\mathrm{RR}=5.0$ CI 3.0-8.6) although the authors could not confirm from the data if the ALM actually developed at the original site of injury. In an earlier study, Briggs et al[22] reviewed a number of cases but suggested that incidental injury to the foot merely drew the patients attention to a pre-existing foot problem. Kaskel et al[23] suggested that trauma in acral areas such as the foot were to be expected more frequently and could find no evidence to identify trauma as an aetiology.

The prognosis of the disease, as with other sub-types of melanoma, is determined by the Breslow thickness of the lesion at diagnosis[24]. It has been suggested that ALM itself carries a worse prognosis than other melanoma often as lesions are recognised later than melanoma on other body sites[25]. Following a number of cases late diagnosis occurring at a tertiary care centre, a study was set up to review cases of the disease in an attempt to identify common clinical factors.

\section{Methods}

A database search was undertaken to identify all cases of ALM treated at the tertiary care melanoma centre located in a central London district. From these, notes were selected of patients presenting with a ALM (diagnosed by histology) on the ankle or below. In the period 2000 2006, twenty seven patients were identified and from their records clinical data including gender, age, ethnicity and diagnostic information were gathered and tabulated for review. 


\section{Results}

The cohort of patients totalled 27 (20 female and 7 male) with a female ratio of nearly $3: 1$. The patients' age at diagnosis ranged from 35 to 96 years. The average age of the patient at was 62.7 with no age difference between men and women (62.5 versus 62.8 respectively). The majority of patients reported their ethnicity as white $(\mathrm{n}=16)$ in addition there were 7 Afro-Caribbean, 1 Chinese/Oriental and 3 unrecorded. Although not always recorded, patients had been reviewed at a number of other clinics with their lesions prior to reaching the dermatology department with a definitive diagnosis. These included a range of specialities - general practice $(n=5)$, podiatry/chiropody ( $n$ $=9)$, vascular clinics $(n=2)$, diabetology $(n=1)$ and plastic surgery $(n=1)$.

Nineteen of the lesions were reported on the right foot and eight on the left. All male patients exhibited ALM on their right foot only. The majority of lesions were located on the plantar surface (62\%) with 2 on the ankle, 2 on the dorsum of the foot, 1 on the digit and 4 located in the nail bed (with 2 in the hallux and 2 in the fifth toe nail bed). One lesion site was stated simply as being on the "foot" (see table 1 ). Twenty-one $(78 \%)$ of the lesions were reported as melanotic, three amelanotic $(11 \%)$ and three $(11 \%)$ were unknown.

Data on the time from the patient first recognising something on their foot to diagnosis was available for 19 patients. The average time for women was 12.5 months versus 14.5 months in males. The most reported symptoms from patients were change in size and bleeding (see table 2). A number of lesions were misdiagnosed as warts $(n=4)$. Lesion thickness at diagnosis ranged from 0.84 $\mathrm{mm}$ to $13.30 \mathrm{~mm}$. The mean thickness for women being $3.68 \mathrm{~mm}(\mathrm{n}=16)$ versus $4.41 \mathrm{~mm}$ in males $(\mathrm{n}=6)$.

Table I: Summary of locations of ALM in 27 patients

\begin{tabular}{lc}
\hline \multicolumn{1}{c}{ Location } & Number \\
\hline Plantar Surface & 17 \\
Plantar Forefoot 6 & 6 \\
(4 located under Ist met head.) & 5 \\
Plantar Midfoot & 6 \\
Plantar Heel & 2 \\
Dorsum of the foot & 2 \\
Ankle & 4 \\
Nail Bed & \\
(2 hallux, 2 fifth toe) & \\
Digit (excluding nail unit) & 1 \\
Not Known & 1 \\
\hline Total & 27 \\
\hline
\end{tabular}

Table 2: Reported symptoms/diagnoses (2I patients). Reported symptom

\begin{tabular}{lc}
\hline \multicolumn{1}{c}{ Symptoms } & Number \\
\hline Change in Size & 8 \\
Bleeding & 4 \\
Change in colour & 2 \\
Change in form & 2 \\
Pain & $\mathrm{I}$ \\
Itching & $\mathrm{I}$ \\
& \\
Previous Diagnoses & \\
Wart & 4 \\
Fungal Infection & $\mathrm{I}$ \\
Haematoma & $\mathrm{I}$ \\
Ulcer & $\mathrm{I}$ \\
\hline
\end{tabular}

\section{Discussion}

This set of patients represents a small cohort $(n=27)$ of a population from an urban area with a high ethnic mix. Interestingly, despite the wide ethnic diversity of the local area, a high proportion of this cohort were white $(69 \%)$. Despite the wide spread of ages (35-96), the average age of the patient in this study was 62.6 years which concurs with similar studies[26,27] that ALM is most frequent in the 60-70 age group[25]. ALM appears to occur in an older age group, other types of melanoma having a peak incidence around 50 years of age, albeit with a wider age spread[2]. The female preponderance to ALM was 2.8:1 slightly higher than other published data [26-28] but still confirms that $\mathrm{MM}$ is a disease more common in females $[3,10]$.

Within this study, the prime location for ALM was the plantar surface $(65 \%)$, with 4 of these occurring under the first metatarsal head. A smaller number were seen in nail beds, ankle and dorsum of the foot. A similar prevalence pattern for the plantar area has been reported by Soon et al[27](61\%) and Kuchelmeister[25] (65\%) with subungual lesions making up a smaller percentage of all cases of ALM. The four sub-ungual tumours in this study were located exclusively on the hallux $(50 \%)$ and fifth toe $(50 \%)$. The hallux has been consistently reported to be the most common area for sub-ungual lesions in the foot. Possible reasons for this are two-fold. Firstly, the hallux may be the most prevalent location owing to the larger proportion of nail tissue in this area. Secondly, one could debate the role of trauma. The hallux is typically an area of the forefoot more prone to abuse from footwear and one-off injury. In one case series from Germany, 6 patients with ALM reported tight footwear as a possible causative agent[23]. The authors went on to discuss that patients with acral melanoma tended to report a high rate of trauma compared to those with melanoma at other sites but this was not found to be statistically significant. 
Furthermore, one could hypothesize, if physical trauma was associated with melanoma, one would expect the foot show a more significant proportion of lesions on the foot as a result of the forces of weight bearing and locomotion.

Early recognition is the key to improving survival rates[29]. As cutaneous melanoma is a visible disease, both the patient and practitioner play a major role in recognising suspicious lesions. Initially, the time taken to reach a diagnosis depends on the patient's ability to recognise and seek professional advice. Secondly, diagnosis depends on the professional's capacity to recognise the lesion. Data were available for 19 patients showing that the time from first noticing a lesion to diagnosis ranged from 1 - 36 months, which shows similarities to other studies of patients with ALM[26]. Reasons for the delay were not examined in this study but have been reviewed by Richard et el[30]. In a series of 590 patients they examined the reasons for delay in melanoma diagnosis and discovered that male gender, increasing age and a low educational level were all risk factors for a later presentation to physicians. In a second paper[31] examining physician delays, acral locations and lack of lesion pigmentation were factors more likely to lead to a delay in diagnosis by a physician, particularly lesions in acral locations without pigmentation.

Within this study, symptoms or initial diagnoses were recorded for 21 patients. The most common reported symptom was a change in the size of the lesion $(38 \%)$ followed by bleeding (19\%), change in colour $(9 \%)$ and change lesion form (becoming raised/nodular) (9\%). Bleeding is a common feature in melanoma which have entered a vertical growth phase and have become ulcerated[2] and may represent a feature of advanced disease. The average lesion thickness in patients reporting bleeding was significantly higher in those not reporting it (mean thickness $6.13 \mathrm{~mm}$ v $3.8 \mathrm{~mm}$ ) although due to the small numbers involved it was difficult to draw firm conclusions.

Seven of the twenty one lesions (33\%) were initially misdiagnosed as other conditions (warts, a fungal infection, haematoma and an ulcer). Numerous papers have highlighted conditions including warts, tinea pedis, ulceration, infection, paronychia, haematoma, onychomycosis, ischaemic necrosis, pyogenic granuloma, ganglions and blisters which have been later discovered to be ALM [27,28,32-36]. Misdiagnosis is a common feature of melanoma on the foot but ALM in particular has been shown to be more likely mis-diagnosed than other subtypes of the disease[37]. Delays can in turn lead to a poorer prognosis for the patient. The misdiagnosis rate in this study was $33 \%$, other have reported rates of between $33 \%-67 \%[27,38]$.
It is appreciated that the results of this study represent a retrospective review of patient case notes which have some inherent bias - in particular that this data was collected at a tertiary centre where possibly only more complex cases are seen. However, in view of the relative rarity of the condition, twenty-six cases represent a sizeable cohort, which has been shown to be concurrent when compared to literature on this topic.

This paper has highlighted an uncommon but serious lesion which may present for the first time to Chiropodists and Podiatrists. One third of the lesions, in the presented cohort, were seen prior to diagnosis by a chiropodist or podiatrist. Unfortunately, typical features of melanoma as exhibited by the "ABCDE" rule may not be present in a proportion of ALM and so misdiagnosis remains a significant risk. Therefore it is important to remain vigilant and where there is clinical suspicion, patients should be referred for a prompt dermatological opinion. In suggesting ways to heighten awareness, the typical patient profile should be borne in mind as well as continuing the patient health education message. In addition, dermoscopy has been demonstrated as a useful, noninvasive technique to increase sensitivity in acral lesions[39]improving early recognition.

\section{Conclusion}

Acral lentigious melanoma is an uncommon malignant tumour which can occur on the foot. This study provided clinical data from 27 cases based on a mainly white, urban population. A third of cases in this series were misdiagnosed before reaching the skin clinic with a proportion of patients having been seen by a number of specialities prior to diagnosis. Lesions were most common on the plantar surface $(62 \%)$. The average time from patients first noticing something to diagnosis was 13.5 months. The most common reported symptoms were a enlargement of the lesion (38\%) and bleeding (19\%). Further studies are required to better understand the aetiology and pathology of this unusual but serious tumour.

\section{Competing interests}

The authors declare that they have no competing interests.

\section{Authors' contributions}

Please see sample text in the instructions for authors.

\section{Acknowledgements}

The authors wish to acknowledge the help of Sally King at St Thomas' in identifying patient cases.

\section{References}

I. Lens MB, Dawes M: Global perspectives of contemporary epidemiological trends of cutaneous malignant melanoma. British Journal of Dermatology 2004, I 50: I79- 185.

2. Bishop JN, Bataille V, Gavin A, Lens M, Marsden J, Mathews T, Wheelhouse $C$ : The prevention, diagnosis, referral and manage- 
ment of melanoma of the skin: concise guidelines. Clin Med 2007, 7(3):283-290

3. UK Skin Cancer mortality statistics [http://info.cancerresear chuk.org/cancerstats/types/skin/mortality/]

4. Australian Institute of Health and Welfare (AIHW) \& Australasian Association of Cancer (AACR): Cancer in Australia: an overview 2006 Canberra: AlHW; 2007.

5. Soong SJ, Shaw HM, Balch CM, McCarthy WH, Urist MM, Lee JY: Predicting survival and recurrence in localized melanoma: a multivariate approach. World J Surg 1992, 16:191-195.

6. Barnes B, Seigler H, Saxby T, Kocher M, Harrelson J: Melanoma of the foot. J Bone Joint Surg AM 1994, 76:892-898.

7. Clark WH Jr, From L, Bernardino EA, Mihm MC: The Histogenesis and Biologic Behavior of Primary Human Malignant Melanomas of the Skin. Cancer Res 1969, 29:705-727.

8. Reed R: Acral lentiginous melanoma. In New concepts in surgical pathology of the skin Edited by: Hartmann W, Reed R. New York: Wiley; 1976:89-90.

9. Elwood J, Gallagher R, Hill G, Spinelli J, Pearson J, Threlfall P: Pigmentation and skin reaction to sun as risk factors for cutaneous melanoma: Western Canada Melanoma Study. British Medical Journal I984, 288(64I I):99-I02.

10. Hudson DA, Krige JEJ, Stubbings H: Plantar melanoma: Results of treatment in three population groups. Surgery 1998, 1 24:877-882.

II. Stalkup JR, Orengo IF, Katta R: Controversies in Acral Lentiginous Melanoma. Dermatologic Surgery 2002, 28: I05I-1059.

12. Chang JW, Yeh KY, Wang CH, Yang TS, Chiang HF, Wei FC, Kuo TT, Yang CH: Malignant melanoma in Taiwan: a prognostic study of I8I cases. Melanoma Res 2004, I 4:537-54I.

13. Chen YJ, Wu CY, Chen JT, Shen JL, Chen CC, Wang HC: Clinicopathologic analysis of malignant melanoma in Taiwan. J Am Acad Dermatol 1999, 41:945-949.

14. Collins RJ: Melanoma in the Chinese of Hong Kong. Emphasis on volar and subungual sites. Cancer 1984, 54:1482-1488.

15. Luk NM, Ho LC, Choi CL, Wong KH, Yu KH, Yeung WK: Clinicopathological features and prognostic factors of cutaneous melanoma among Hong Kong Chinese. Clinical and Experimental Dermatology 2004, 29:600-604.

16. Ishihara K, Saida T, Yamamoto A: Updated statistical data for malignant melanoma in Japan. Int J Clin Oncol 200 I, 6: 109-II6.

17. Al-Maghrabi JA, Al-Ghamdi AS, Elhakeem HA: Pattern of skin cancer in Southwestern Saudi Arabia. Saudi Med J 2004, 25:776-779.

18. Muchmore JH, Mizuguchi RS, Lee C: Malignant melanoma in American black females: an unusual distribution of primary sites. J Am Coll Surg 1996, I 83:457-465.

19. Bellows CF, Belafsky P, Fortgang IS, Beech DJ: Melanoma in African-Americans: trends in biological behavior and clinical characteristics over two decades. I Surg Oncol 200I, 78:10-16.

20. Green A, McCredie M, MacKie R, Giles G, Young P, Morton C, Jackman $L$, Thursfield $V$ : A case-control study of melanomas of the soles and palms (Australia and Scotland). Cancer Causes Control 1999, 10:21-25.

21. Wiecker TS, Luther H, Buettner P, Bauer J, Garbe C: Moderate sun exposure and nevus counts in parents are associated with development of melanocytic nevi in childhood. Cancer 2003, 97:628-638.

22. Briggs JC: The role of trauma in the aetiology of malignant melanoma: a review article. BrJ Plast Surg 1984, 37:514-5 16.

23. Kaskel P, Kind P, Sander S, Peter RU, Krahn G: Trauma and melanoma formation: a true association? British Journal of Dermatology 2000, 143:749-753.

24. Breslow A: Prognostic Factors in the Treatment of Cutaneous Melanoma. Journal of Cutaneous Pathology 1979, 6:208-2I2.

25. Kuchelmeister C, Schaumburg-Lever G, Garbe C: Acral cutaneous melanoma in caucasians: clinical features, histopathology and prognosis in $1 / 2$ patients. 2000, I43:275-280.

26. Phan A, Touzet S, Dalle S, Ronger-Savle S, Balme B, Thomas L: Acral lentiginous melanoma: a clinicoprognostic study of 126 cases. British Journal of Dermatology 2006, 155:561-569.

27. Soon SL, Solomon AR Jr, Papadopoulos D, Murray DR, McAlpine B, Washington CV: Acral lentiginous melanoma mimicking benign disease: the Emory experience. J Am Acad Dermatol 2003, 48: $183-188$
28. Fortin PT, Freiberg AA, Rees R, Sondak VK, Johnson TM: Malignant melanoma of the foot and ankle. J Bone Joint Surg Am 1995, 77:1396-1403.

29. Roberts D, Anstey A, Barlow R, Cox N: UK guidelines on the management of cutaneous melanoma. British Journal of Dermatology 2002, 146:7-17.

30. Richard MA, Grob JJ, Avril MF, Delaunay M, Gouvernet J, Wolkenstein P, Souteyrand P, Dreno B, Bonerandi J], Dalac S, et al.: Delays in diagnosis and melanoma prognosis (I): the role of patients. Int J Cancer 2000, 89:27I-279.

31. Richard MA, Grob JJ, Avril MF, Delaunay M, Gouvernet J, Wolkenstein P, Souteyrand P, Dreno B, Bonerandi J], Dalac S, et al.: Delays in diagnosis and melanoma prognosis (II): the role of doctors. Int J Cancer 2000, 89:280-285.

32. Gregson CL, Allain TJ: Amelanotic malignant melanoma disguised as a diabetic foot ulcer. Diabetic Medicine 2004, 21:924-927.

33. Serarslan G, Akcaly C, Atik E: Acral lentiginous melanoma misdiagnosed as tinea pedis: a case report. Int J Dermatol 2004, 43:37-38.

34. Rosen $\mathrm{T}$ : Acral lentigious melanoma misdiagnosed as verruca plantaris: a case report. Dermatol Online J 2006, I 2(4):3.

35. Dalmau J, Abellaneda C, Puig S, Zaballos P, Malvehy J: Acral Melanoma Simulating Warts: Dermoscopic Clues to Prevent Missing a Melanoma. Dermatologic Surgery 2006, 32:1072-1078.

36. Valdes A, Kulekowskis A, Curtis L: Case Report: Amelanotic Melanoma Located on the Lower Extremity (letter). Am Fam Physician 2007, 76:1614.

37. Metzger S, Ellwanger U, Stroebel W, Schiebel U, Rassner G, Fierlbeck $\mathrm{G}$ : Extent and consequences of physician delay in the diagnosis of acral melanoma. Melanoma Res 1998, 8:18I-186.

38. Bennett DR, Wasson D, MacArthur JD, McMillen MA: The effect of misdiagnosis and delay in diagnosis on clinical outcome in melanomas of the foot. J Am Coll Surg 1994, 179:279-284.

39. Bristow I: Dermoscopy - a technique for Podiatrists to assess pigmented lesions of the foot. World Congress in Podiatry. Denmark 2007.

Publish with BioMed Central and every
scientist can read your work free of charge
"BioMed Central will be the most significant development for
disseminating the results of biomedical research in our lifetime. "
Sir Paul Nurse, Cancer Research UK
Your research papers will be:
• available free of charge to the entire biomedical community
• peer reviewed and published immediately upon acceptance
• cited in PubMed and archived on PubMed Central
• yours - you keep the copyright
Submit your manuscript here:
http://www.biomedcentral.com/info/publishing_adv.asp

